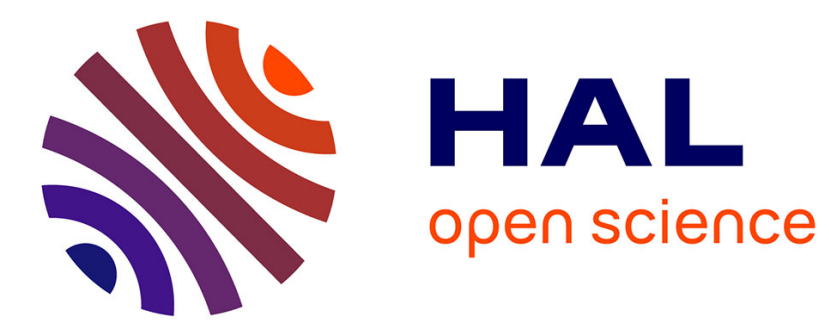

\title{
Systematic design of an extractive distillation for maximum-boiling azeotropes with heavy entrainers
}

Weifeng Shen, Lichun Dong, Shun'An Wei, Jie Li, Hassiba Benyounes, Xinqiang You, Vincent Gerbaud

\section{- To cite this version:}

Weifeng Shen, Lichun Dong, Shun'An Wei, Jie Li, Hassiba Benyounes, et al.. Systematic design of an extractive distillation for maximum-boiling azeotropes with heavy entrainers. AIChE Journal, 2015, vol. 61 ( $\left.\mathrm{n}^{\circ} 11\right)$, pp. 3898-3910. 10.1002/aic.14908 . hal-01343157

\section{HAL Id: hal-01343157 \\ https://hal.science/hal-01343157}

Submitted on 7 Jul 2016

HAL is a multi-disciplinary open access archive for the deposit and dissemination of scientific research documents, whether they are published or not. The documents may come from teaching and research institutions in France or abroad, or from public or private research centers.
L'archive ouverte pluridisciplinaire HAL, est destinée au dépôt et à la diffusion de documents scientifiques de niveau recherche, publiés ou non, émanant des établissements d'enseignement et de recherche français ou étrangers, des laboratoires publics ou privés. 


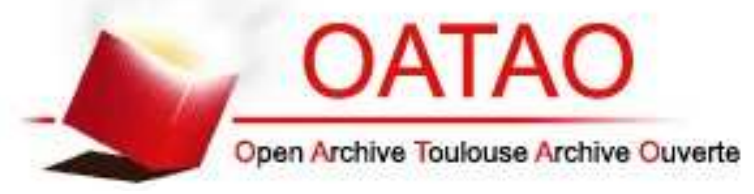

\section{Open Archive TOULOUSE Archive Ouverte (OATAO)}

OATAO is an open access repository that collects the work of Toulouse researchers and makes it freely available over the web where possible.

This is an author-deposited version published in : http://oatao.univ-toulouse.fr/ Eprints ID : 15858

To link to this article : DOI : $10.1002 /$ aic. 14908

URL : http://dx.doi.org/10.1002/aic.14908

To cite this version : Shen, Weifeng and Dong, Lichun and Wei, Shun'an and Li, Jie and Benyounes, Hassiba and You, Xinqiang and Gerbaud, Vincent Systematic design of an extractive distillation for maximum-boiling azeotropes with heavy entrainers. (2015) AIChE Journal, vol. 61 ( $\mathrm{n}^{\circ}$ 11). pp. 3898-3910. ISSN 0001-1541

Any correspondence concerning this service should be sent to the repository administrator: staff-oatao@ listes-diff.inp-toulouse.fr 


\begin{abstract}
Weifeng Shen
School of Chemistry and Chemical Engineering, Chongqing University, Chongqing 400044, China

Key Laboratory of Low-Grade Energy Utilization Technologies \& Systems of the Ministry of Education, Chongqing University, Chongqing 400044, China

Dept. of Chemical and Biomolecular Engineering, Clarkson University, Potsdam, NY,USA
\end{abstract}

Lichun Dong and Shun'an Wei

School of Chemistry and Chemical Engineering, Chongqing University, Chongqing 400044, China

Key Laboratory of Low-Grade Energy Utilization Technologies \& Systems of the Ministry of Education, Chongqing University, Chongqing 400044, China

\title{
Jie Li
}

State Key Laboratory of Multiphase Complex Systems, Institute of Process Engineering, Chinese Academy of Sciences, Beijing, 100190, China

\section{Hassiba Benyounes}

U.S.T. Oran, Laboratoire de chimie physique des matériaux, catalyse et environnement, Oran, Algérie

\section{Xinqiang You and Vincent Gerbaud}

Université de Toulouse, INP, UPS, LGC (Laboratoire de Génie Chimique), 4 allée Emile Monso, F-31432 Toulouse Cedex 04, France

CNRS, LGC (Laboratoire de Génie Chimique), F-31432 Toulouse Cedex 04, France

Extractive distillation is one of the most attractive approaches for separating azeotropic mixtures. Few contributions have been reported to design an extractive distillation for separating maximum-boiling azeotropes and no systematic approaches for entrainer screening have been presented. A systematic approach to design of two-column extractive distillation for separating azeotropes with heavy entrainers has been proposed. A thermodynamic feasibility analysis for azeotropes with potential heavy entrainers was first conducted. Then, five important properties are selected for entrainer evaluation. Fuzzy logic and develop membership functions to calculate attribute values of selected properties have been used. An overall indicator for entrainer evaluation is proposed and a ranking list is generated. Finally, the top five entrainers from the ranking list have been selected and use process optimization techniques to further evaluate selected entrainers and generate an optimal design. The capability of the proposed method is illustrated using the separation of acetone-chloroform azeotropes with five potential entrainers.

Keywords: extractive distillation, entrainer screening, membership function, process optimization

\section{Introduction}

In most nonideal azeotropic mixtures, the predominant nonideality occurs because of molecular interactions. If molecules repel each other, the activity coefficients are usually greater than unity (called a "positive deviation" from Raoult's law), in this case, minimum boiling $\left(T_{\min }\right)$ azeotropes could be gener-

Correspondence concerning this article should be addressed to $\mathrm{J}$. $\mathrm{Li}$ at liveinsky@gmail.com ated. On the contrary, if molecules attract each other, activity coefficients are usually less than unity (negative deviation) and the mixtures may forms maximum boiling $\left(T_{\max }\right)$ azeotropes. ${ }^{1}$ Several processes can be used in chemical industries to separate nonideal azeotropic or close-boiling binary mixtures $\mathrm{A}-\mathrm{B}$, which are azeotropic distillation, ${ }^{1,2}$ pressure swing distillation, ${ }^{3-6}$ and extractive distillation process. ${ }^{1}$ In azeotropic distillation, a third component $\mathrm{E}$ is added to the feed (A-B). A or B components become either a stable or unstable node on the residue curve map in the relevant distillation region, thus being removable as product by either an indirect 
or a direct split, respectively. However, this process is used for the separation of azeotropic mixture only when the boundary is curved enough in azeotropic distillation. ${ }^{2,7}$ The pressure swing distillation is usually used for separating some azeotrope binary mixtures whose azeotropic composition considerably varies or the azeotrope disappears when the system pressure is changed. It is reported that the pressure swing distillation is unattractive for the separation of the maximumboiling azeotrope acetone-chloroform since its composition is not very sensitive to pressure changes. ${ }^{1}$ Accordingly, extractive distillation becomes one of the most attractive approaches for the separation of azeotropic mixtures, and the review on the comparison between the extractive and pressure swing distillation can be found in the literatures. ${ }^{8-10}$

A lot of literature studies have concerned the design extractive distillation for the effective separation of minimumboiling azeotropic mixtures such as ethanol-water system ${ }^{11}$ and acetone-methanol mixture. ${ }^{12-15}$ Most of these studies focus on issues related with entrainer screening and process optimization. Since the entrainer selection issue strongly determines the process feasibility, selecting an efficient entrainer is the key step in determining whether an extractive distillation process is a promising separation technique or not. ${ }^{16,17}$ Thermodynamic insight from the knowledge of univolatility lines and the analysis of residue curve map has been used to study feasibility of batch ${ }^{18-22}$ and continuous ${ }^{12,23-25}$ extractive distillation for the separation of azeotropes with heavy, light, or intermediate entrainers, giving rise to extractive separation classes, which can be used to indicate direct or indirect split extractive process configurations and products. ${ }^{26}$ Once an extractive separation class is identified, a variety of feasible entrainers can be selected. However, it is helpful to develop a systematic approach for screening these selected entrainers with the overall consideration of their cost, stability, selectivity, and ability to interact with the components of the fresh mixture that could cause their relative volatilities to either increase or decrease.

To the best of our knowledge, very few contributions have been reported to design extractive distillation for the separation of maximum boiling azeotropes in continuous mode. Some literature have concerned the batch extractive distillation process. ${ }^{18,27-31}$ The most important contribution is from Luyben, ${ }^{32}$ who designed an extractive distillation process for the separation of the maximum boiling azeotrope acetone (A)chloroform (B) with a heavy entrainer E, belonging to 1.0-2 separation class. However, Luyben ${ }^{32}$ only considered dimethylsulfoxid (DMSO) as the qualified entrainer for acetone (A)-chloroform (B) system to achieve the specified separation target. No systematic approaches for entrainer screening have been presented in his work. Therefore, in this article, we propose a systematic approach for entrainer screening in design of two-column extractive distillation for the separation of maximum-boiling azeotropes with heavy entrainers. Thermodynamic feasibility analysis is first conducted for entrainers. Then, we use fuzzy logic and develop membership functions to calculate attribute values of selected five important properties. Finally, an indicator "total score" for entrainer evaluation is proposed, which is defined as the summation of weighted attribute values. A ranking list of the entrainers is generated based on their "total score." Process optimization techniques are used to further evaluate the top five entrainers from the ranking list and optimal designs of extractive distillation process using the best entrainers are generated. The proposed

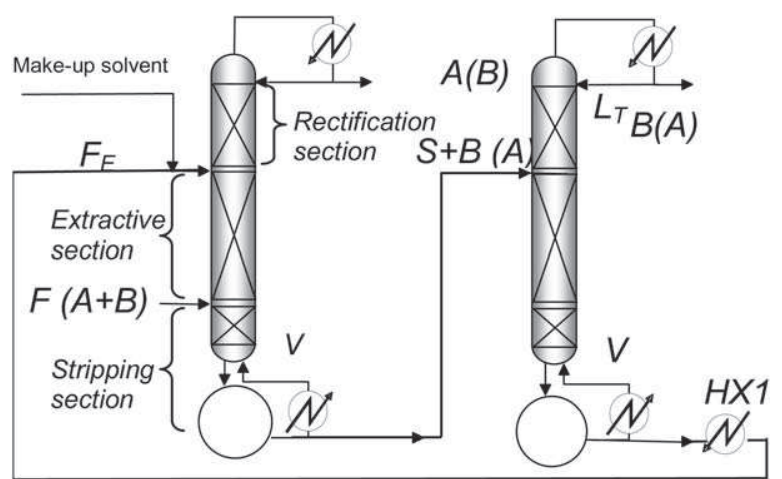

Figure 1. A typical extractive distillation process flow sheet.

method is illustrated using the separation of acetone/chloroform azeotropes with five heavy entrainers (DMSO, chlorobenzene, ethylene glycol [EG], $o$-xylene, and benzene). It should be noted that systematic entrainer screening is a fundamental, interesting, and significant problem in design of twocolumn extractive distillation for the separation of maximumboiling azeotropes with heavy entrainers. We are the first one to propose a systematic approach using fuzzy logic for entrainer screening and develop weighted membership functions for entrainer evaluation.

\section{Extractive Distillation Process}

A typical flow sheet for the extractive distillation process is shown in Figure 1. The extractive distillation process typically features an extractive column and a regeneration column. The extractive column is fed with azeotropic $(\mathrm{A}+\mathrm{B})$ and entrainer (E) mixture. In extractive distillation, the entrainer is fed at a location different from the main azeotropic feed, resulting in an extractive section in addition to the usual stripping and rectifying sections. Light product $\mathrm{A}$ is recovered from the distillate and the mixture $\mathrm{B}+\mathrm{E}$ is fed to the entrainer regeneration column. The regeneration column removes product $\mathrm{B}$ from the distillate and recycles the entrainer from the bottom. The recycled entrainer is cooled before going back to the extractive column to a temperature preset in the extractive column. The process needs a makeup to compensate entrainer losses along with products. The two columns are assumed to be operated at constant pressure while pressure drop is neglected in each column.

\section{Systematic approach to design of extractive distillation}

The proposed approach to the design of an extractive distillation for the separation of maximum-boiling azeotropes with heavy entrainers is illustrated in Figure 2.

In Figure 2, we first conduct a process feasibility analysis on residue curve maps and volatility orders of the ternary AB-E system. Thermodynamics insight from these analysis help to identify the feasibility with promising entrainer candidates for the separation of azeotropic mixtures A-B from all potential entrainers (i.e., Step 1 in Figure 2). Second, physicochemical and process-related properties of entrainer candidate's desired properties are analyzed (i.e., Step 2 in Figure 2) and five important properties are selected for entrainer evaluation. Third, membership functions are developed and used to calculate attribute values of selected five important properties. These attribute values are weighted and summed together to generate an indicator "total score" for entrainer ranking (i.e., 


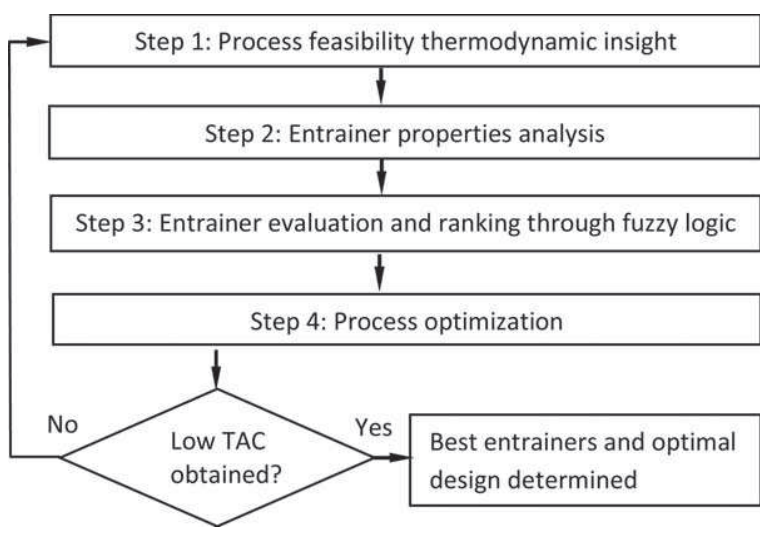

Figure 2. Block flow diagram of the proposed design method.

Step 3 in Figure 2). In the fourth step, top five entrainers from the ranking list are further evaluated through a rigorous process optimization using sequential quadratic programming (SQP) method. Steps 1 through 4 are iterated through until a low total annualized cost (TAC) is achieved. Finally, we determine the best entrainers and corresponding optimal designs of two-column extractive distillation process for the separation of maximum-boiling azeotropes. We next present each step in detail.

\section{Process feasibility thermodynamic analysis}

Conventionally, an entrainer $\mathrm{E}$ has a higher boiling temperature than A and B. ${ }^{1,33}$ However, light or intermediate boiling entrainers can be used as well. ${ }^{34}$ Inspired by the work of Laroche et al., ${ }^{23}$ Rodríguez-Donis et al. ${ }^{18,19}$ proposed a general feasibility criterion for batch extractive distillation after analyzing the ternary diagram $\mathrm{A}-\mathrm{B}-\mathrm{E}$ residue curve map and the location of the volatility order regions set by univolatility curves. ${ }^{20}$ It states that "homogeneous batch extractive distillation process of a A-B mixture with entrainer (E) feeding is feasible if there exists a residue curve connecting $\mathrm{E}$ to $\mathrm{A}$ or $\mathrm{B}$ following a decreasing (a) or increasing (b) temperature direction inside the region where A or B are the most volatile (a) or the heaviest (b) component of the mixture."18,19 This criterion has already been extended to continuous extractive distilla- tion. $^{24,25}$ Application of the thermodynamic criterion provide the information on product feasibility, which product goes up or down, using a rectifying or stripping column, operating parameter value, and entrainer efficiency.

Conversely, we use ternary diagram to illustrate feasible regions and topological features of ternary systems. Azeotropic ternary diagrams properties have been well studied and are classified according to Serafimov's class, which also indicates the occurrence among known ternary diagrams. ${ }^{35}$ Typical azeotropic ternary systems in extractive distillation can generally be classified into 1.0-1a class and 1.0-2 class. While 1.0-1a class is defined to separate a minimum boiling azeotrope using a heavy entrainer or a maximum boiling azeotrope with a light entrainer, 1.0-2 class is defined for the separation of a minimum boiling azeotrope with a light entrainer or a maximum boiling azeotrope with a heavy entrainer. Our previous work ${ }^{36}$ has concluded that up to $53 \%$ of azeotropic mixtures that are suitable for separation using extractive distillation belong to Serafimov's classes including 0.0-1 (lowrelative-volatility mixtures), ${ }^{37} 1.0-1 \mathrm{a}, 1.0-1 \mathrm{~b}, 1.0-2$ (azeotropic mixtures with light, intermediate, or heavy entrainers forming no new azeotrope), ${ }^{18,27,28,38} 2.0-1,2.0-2 \mathrm{a}, 2.0-2 \mathrm{~b}, 2.0$ $2 c$ (azeotropic mixtures with an entrainer forming one new azeotrope). ${ }^{20}$

Corresponding to the maximum boiling azeotrope separation with a heavy entrainer, Serafimov's class 1.0-2 ternary diagram is represented on Figure 3. Its occurrence in literature is $8.5 \% .^{35}$ The 1.0-2 class diagram displays a residue curve map (RCM) stable separatrix, which divides the composition space into two distillation regions. The outstanding feature is that the general feasibility criterion is fulfilled by both $\mathrm{A}$ and $\mathrm{B}$ at the same time, wherever the univolatility curve $\alpha_{\mathrm{AB}}=1$ lies. Therefore, they can both be distillate products, depending on the location of the global feed composition $x_{\mathrm{F}}+x_{\mathrm{FE}}$, either in $B \mathrm{AE}$ and $B \mathrm{EA}$ (B product) or in $A \mathrm{BE}$ and $A \mathrm{~EB}$ (A product). However, two subcases arise, as the $\alpha_{\mathrm{AB}}=1$ location sets different maximum entrainer-feed flow rate value for either $A$ or B. For the case (1.0-2)-M1 (Figure 3a), there exists a maximum entrainer-feed flow rate $\left(F_{\mathrm{E}} / V\right)_{\max , \mathrm{A}}$ for separating $\mathrm{A}$ as the curve $\alpha_{\mathrm{AB}}=1$ intercepts the edge A-E. There is no limit entrainer-feed flow rate for separating B. For the case (1.0-2)M2 (Figure 3b), behaviors related to A and B are reversed.
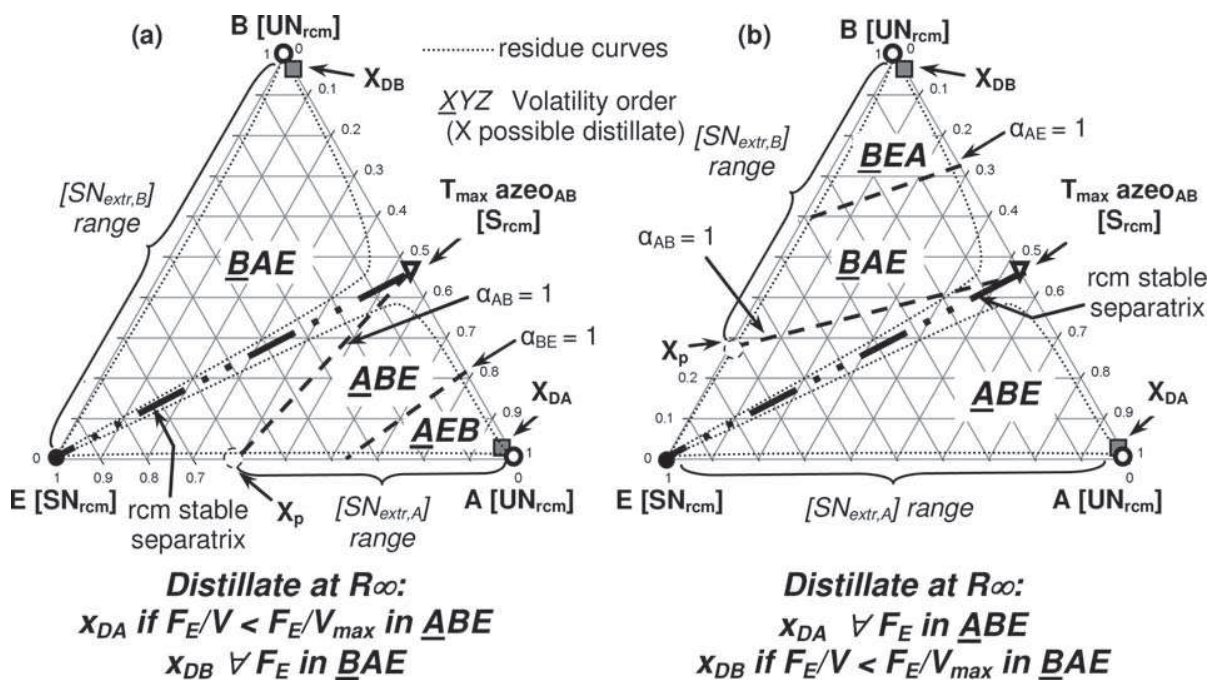

Figure 3. Thermodynamic features of 1.0-2 mixtures with respect to the separation of a maximum boiling azeotrope with a heavy entrainer. 


\section{Entrainer property analysis}

As discussed before, the effectiveness of an extractive distillation process largely relies on an efficient (i.e., economic) extractive entrainer. The performance of an entrainer is often evaluated based on its relative volatility, ${ }^{13,39-41}$ solubility power, ${ }^{13,39-41}$ boiling point, ${ }^{13}$ molecular weight, and melting point. $^{39}$ Inspired from these studies, we summarize that a potential entrainer should be evaluated over properties in three categories: (1) pure entrainer properties such as boiling point, vapor pressure, molar volume, melting point, and critical properties; (2) process-related properties including relative volatility, solubility power, phase stability criterion, ${ }^{42}$ and (3) Sustainability-related criteria such as $\mathrm{LC}_{50}$, environmental waste, impact, health, and safety. From an economic point of view, relative volatility and solubility power are the two most important properties for the evaluation of an entrainer performance. ${ }^{13,39-41,43,44}$ The third important property is boiling point. ${ }^{13,44}$ The fourth important properties are molecular weight and melting point. ${ }^{40}$ The molar volume of the (heavy) entrainer is interesting mainly in the case of batch extractive distillation where it is accumulated in the reboiler and hence the volume of the entrainer fed decreases the amount of binary charge to be processed in one batch. ${ }^{45}$ In continuous extractive distillation, it is interesting only from the point of view of its storage. Therefore, we select boiling point, melting point, vapor pressure, and molecular weight from the first category. In the second group, we select relative volatility and entrainer power, which are defined in the following. Phase stability and sustainability-related criteria from the third group are not considered in this article.

The relative volatility, denoted as $\alpha_{A, B}$, is defined as the ratio of vapor-liquid equilibrium (VLE) distribution constant. That is

$$
\alpha_{\mathrm{A}, \mathrm{B}}=\frac{K_{\mathrm{A}}}{K_{\mathrm{B}}}=\frac{y_{\mathrm{A}}}{y_{\mathrm{B}}} \frac{x_{\mathrm{B}}}{x_{\mathrm{A}}}=\frac{\gamma_{\mathrm{A}}}{\gamma_{\mathrm{B}}} \frac{P_{\mathrm{A}}^{0}}{P_{\mathrm{B}}^{0}}
$$

where $\gamma_{\mathrm{A}}$ and $\gamma_{\mathrm{B}}$ denote activity coefficients of components A and $\mathrm{B}$ in a liquid phase, respectively; $P_{\mathrm{A}}^{0}$ and $P_{\mathrm{B}}^{0}$ stand for saturated vapor pressures of $\mathrm{A}$ and $\mathrm{B}$, respectively.

Although $\alpha_{A, B}$ varies with compositions, ${ }^{22}$ it is custom to use the infinite dilution ratio as follows

$$
\alpha_{\mathrm{A}, \mathrm{B}}^{\infty}=\frac{\gamma_{\mathrm{A}, \mathrm{S}}^{\infty}}{\gamma_{\mathrm{B}, \mathrm{S}}^{\infty}} \frac{P_{\mathrm{A}}^{0}}{P_{\mathrm{B}}^{0}}
$$

where $\gamma_{\mathrm{A}, \mathrm{S}}^{\infty}$ is the activity coefficient for a trace of species $\mathrm{A}$ in an entrainer, and $\gamma_{\mathrm{B}, \mathrm{S}}^{\infty}$ is the activity coefficient for a trace of species B in an entrainer. The fugacity of pure compound liquid in a reference state was supposed to be equal to the vapor pressure. Note that $\alpha_{\mathrm{A}, \mathrm{B}}$ can also be used to estimate the selectivity ratio of an entrainer. ${ }^{46}$ Therefore, a higher value of $\alpha_{\mathrm{A}, \mathrm{B}}^{\infty}$ indicates that fewer entrainers are required in an extractive process, which can reduce the energy in the extractive column and the total recovery cost in the entrainer recovery column.

The solubility power criterion also called entrainer capacity $S_{p}^{40}$, is defined by Kossack et al. ${ }^{13}$ as follows

$$
S_{\mathrm{P}}=\frac{1}{\gamma_{\mathrm{A}, \mathrm{S}}^{\infty}} \frac{\mathrm{MW}_{\mathrm{A}}}{\mathrm{MW}_{\mathrm{S}}}
$$

Jork et al. $^{47}$ stated that an entrainer with a low capacity often possesses a high selectivity. It is found that the entrainer capacity is in a better agreement with the TAC of optimized

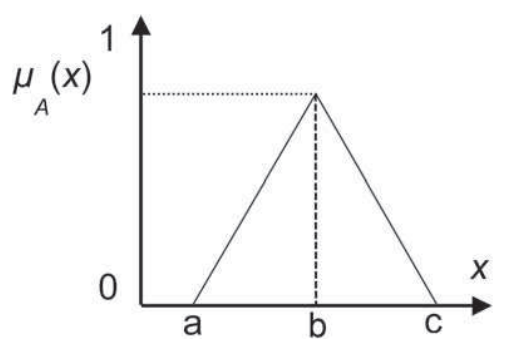

Figure 4. A triangular membership function.

process flow sheet that the selectivity alone. ${ }^{13}$ In addition, from Eq. 3, it is concluded that a small value of the activity coefficient $\gamma_{\mathrm{A}, \mathrm{S}}^{\infty}$ indicating the strong interactions between component $\mathrm{A}$ and an entrainer, can result in a large capacity or solubility power for the entrainer.

\section{Entrainer evaluation and ranking through fuzzy logic}

To implement the aforementioned properties, Kossack et al. ${ }^{13}$ imposed some strict limits on each property to screen out undesired entrainers. To screen the entrainers whose properties satisfy all imposed limits, they are evaluated with the so-called rectification body method the minimum energy demand of each related process. Then they used rigorous mixed-integer nonlinear programming (MINLP) to assess each preliminary design performance with a rigorous MESH (Mass balance equations, Equilibrium equations, Summation of mole fraction equations, and Heat or enthalpy balance equations) model. This requires a huge computational effort.

In the above work, some good entrainers may be eliminated when are out of the bounds set on the property values. However, bearing in mind that property prediction models are inaccurate, some of those candidate should be kept within some tolerance. To achieve this target, we apply a fuzzy logic to represent entrainer property specifications.

Determining appropriate fuzzy membership functions is a key issue in fuzzy logic. The membership function fully defines a fuzzy set and provides a measurement of the degree of similarity of an element (e.g., a property) to a fuzzy set. The membership function maps elements into numerical values in the interval $[0,1]$. While a value of zero implies that the element does not belong to the set, a value of unity means that the element fully belongs to the set. ${ }^{48}$ The membership function can be any form such as triangular, trapezoidal, piecewise-linear, Gaussian, and bell-shaped, which can be chosen by the user according to the characters of target objective or designed using machine learning methods (e.g., artificial neural networks, genetic algorithms, etc.). Figure 4 illustrates a typical triangular member function, which is described using Eq. 4 given below

$$
\mu_{\mathrm{A}}(x)= \begin{cases}0 & \text { if } x \leq a \\ \frac{x-a}{b-a} & \text { if } a \leq x \leq b \\ \frac{c-x}{c-b} & \text { if } b \leq x \leq c \\ 0 & \text { if } x \geq c\end{cases}
$$

where $a, b$, and $c$ represent the $x$ coordinates of three vertices of $\mu_{\mathrm{A}}(x)$ in a fuzzy set A. $a$ is a lower boundary, and $c$ is an upper boundary where membership degree is zero. $b$ represents the center value, where the membership degree is 1 . Usually for each degree a linguistic description is used, for 
example, bad, acceptable, good, and very good. Next, we propose fuzzy membership functions for those five properties.

For the relative volatility under infinite dilution, If $\alpha_{\mathrm{A}, \mathrm{B}}^{\infty}<1$, the entrainer is not suitable because in the case of a maximum azeotrope separation with a heavy entrainer we are concerned with, it indicates that there exists a limit for the entrainer flow rate to recover acetone as distillate. ${ }^{18,24}$ It is considered to be a bad entrainer and $\mu\left(\alpha_{\mathrm{A}, \mathrm{B}}^{\infty}\right)=0$. Conversely, for $1<\alpha_{\mathrm{A}, \mathrm{B}}^{\infty}<2$, an entrainer is treated as acceptable, and the function is given a gain of 0.3. ${ }^{40,49}$ The remaining values $2<\alpha_{\mathrm{A}, \mathrm{B}}^{\infty}<4$ means that an entrainer is good, and the function is gained by an evaluation value of $0.7 .^{40,49}$ If $\alpha_{\mathrm{A}, \mathrm{B}}^{\infty}>4$, the entrainer is considered as very good. The membership functions of relative volatility defined in Eq. 5

$$
\mu\left(\alpha_{\mathrm{A}, \mathrm{B}}^{\infty}\right)= \begin{cases}0 & \text { if } \alpha_{A, B}^{\infty} \leq 1 \\ \frac{0.3\left(\alpha_{\mathrm{A}, \mathrm{B}}^{\infty}-1\right)}{2-1} & \text { if } 1<\alpha_{A, B}^{\infty} \leq 2 \\ \frac{0.7\left(\alpha_{\mathrm{A}, \mathrm{B}}^{\infty}-2\right)}{4-2} & \text { if } 2<\alpha_{A, B}^{\infty} \leq 4 \\ 1 & \text { if } \alpha_{A, B}^{\infty}>4\end{cases}
$$

For the solubility power $\left(S_{\mathrm{p}}\right)$, an entrainer can be considered as very good if $S_{\mathrm{p}}$ is greater than 0.5 . When $S_{\mathrm{p}}$ is less than 0.02 , it indicates a poor capacity entrainer, and therefore, the evaluation value would be $0 .{ }^{40}$ Similarly, the function is evaluated by different degrees of 0.3 and 0.7 , when $S_{\mathrm{p}}$ is between $0.02-0.135$ and $0.135-0.5$, respectively. The membership function of solubility power is defined as follows

$$
\mu\left(S_{\mathrm{p}}\right)= \begin{cases}0 & \text { if } 0<S_{\mathrm{p}} \leq 0.02 \\ \frac{0.3\left(S_{\mathrm{p}}-0.02\right)}{0.135-0.02} & \text { if } 0.02<S_{\mathrm{p}} \leq 0.135 \\ \frac{0.7\left(S_{\mathrm{p}}-0.135\right)}{0.5-0.135} & \text { if } 0.135<S_{\mathrm{p}} \leq 0.5 \\ 1 & \text { if } S_{\mathrm{p}}>0.5\end{cases}
$$

To facilitate the recycling of a heavy entrainer from components with highest boiling point in the regeneration column, its boiling point is usually $30-150 \mathrm{~K}$ higher than that of any component in the mixture to reduce more energy in vaporization of a boiling component. ${ }^{49,50}$ The following membership function of boiling point is established in Eq. 7

$$
\mu\left(T_{\mathrm{b}}\right)= \begin{cases}0 & \text { if } T_{\mathrm{b}} \leq T_{\mathrm{b}}^{\max }+30 \\ \frac{T_{\mathrm{b}}^{\max }+150-T_{\mathrm{b}}}{150-30} & \text { if } T_{\mathrm{b}}^{\max }+30<T_{\mathrm{b}} \leq T_{\mathrm{b}}^{\max }+150 \\ 0 & \text { if } T_{\mathrm{b}} \geq T_{\mathrm{b}}^{\max }+150\end{cases}
$$

where, $T_{\mathrm{b}}^{\max }$ is the highest boiling point among components in the mixture to be separated.

Regarding the entrainer melting point, it is better for an entrainer not to freeze at room temperature, which is taken equal to $303 \mathrm{~K}$. The melting point of an entrainer is considered to be excellent if $T_{\mathrm{m}} \leq 273 \mathrm{~K} .{ }^{51}$ The following membership function of melting point is established in Eq. 8

$$
\mu\left(T_{\mathrm{m}}\right)= \begin{cases}1 & \text { if } T_{\mathrm{m}} \leq 273 \\ \frac{303-x}{303-273} & \text { if } 273 \leq T_{\mathrm{m}} \leq 303 \\ 0 & \text { if } T_{\mathrm{m}} \geq 303\end{cases}
$$

Regarding the molecular weight of an entrainer; it is correlated with other physical properties such as density and boiling point, which are known to increase along with carbon number. $^{52}$ Based on the work from Schwarz and Nieuwoudt ${ }^{53}$ and Takanohashi et al., ${ }^{54}$ we set molecular weight upper limits as $180 \mathrm{~g} / \mathrm{mol}$ for alkane series, and $240 \mathrm{~g} / \mathrm{mol}$ for naphthenic and aromatic hydrocarbons. The membership functions of molecular weight are developed as follows

$$
\mu\left(\mathrm{MW}_{s}\right)= \begin{cases}1-\frac{\mathrm{MW}_{\mathrm{s}}}{180} & \text { if } \quad \mathrm{MW}_{\mathrm{s}} \leq 180 \\ 0 & \text { if } \quad \mathrm{MW}_{\mathrm{s}} \geq 180\end{cases}
$$

(for chain hydrocarbons)

$$
\mu\left(\mathrm{MW}_{s}\right)= \begin{cases}1-\frac{\mathrm{MW}_{\mathrm{s}}}{240} & \text { if } \quad \mathrm{MW}_{\mathrm{s}} \leq 240 \\ 0 & \text { if } \quad \mathrm{MW}_{\mathrm{s}} \geq 240\end{cases}
$$

(for naphthenic and aromatic hydrocarbons)

Now, we create an entrainer evaluation set $U$ with five members $U_{1}, U_{2}, \ldots, U_{5}$, which are for relative volatility, solubility power, boiling point, melting point, and molecular weight, respectively. Each member describes the degrees of a property performance for an entrainer used in an extractive distillation.

$$
U=\left\{U_{1}, U_{2}, U_{3}, U_{4}, U_{5}\right\}
$$

Then, each property attribute value is weighted and the weighted attribute values are summed together to develop a total score indicator, $T_{\text {score }}$, as given in Eq. 12

$$
\begin{aligned}
T_{\text {Score }}= & w_{1} \cdot \mu\left(\alpha_{\mathrm{A}, \mathrm{B}}^{\infty}\right)+w_{2} \cdot \mu\left(S_{\mathrm{p}}\right)+w_{3} \cdot \mu\left(\mathrm{MW}_{\mathrm{s}}\right) \\
& +w_{4} \cdot \mu\left(T_{\mathrm{b}}\right)+w_{5} \cdot \mu\left(T_{\mathrm{m}}\right)
\end{aligned}
$$

where $w_{1}, w_{2}, w_{3}, w_{4}$, and $w_{5}$ denote weight factors for relative volatility, solubility power, molecular weight, boiling point, and melting point, respectively. A higher total score $\left(T_{\text {score }}\right)$ for an entrainer represents better performance.

The weight factors assigned to each property should be chosen to suit the specific problem and evidently affect the final solution. ${ }^{55}$ Based on studies in the literature $13,38,39,43,55,56$ and our own experience, we conclude that the relative volatility, and solubility power are more important than the other properties, and boiling point is more important than molecular weight, and melting point. Therefore, the weight factors for those five properties should satisfy the following relationship,

$$
\begin{aligned}
w_{1} & >w_{4} \\
w_{2} & >w_{4} \\
w_{4} & >w_{3} \\
w_{4} & >w_{5} \\
w_{1}+w_{2}+w_{3} & +w_{4}+w_{5}=1
\end{aligned}
$$

\section{Process optimization}

In the literature, optimal solutions for extractive distillation are first sought using sensitivity analysis on process variables, including reflux ratio, ratio of entrainer flow rate to feed flow rate, distillate flow rate, and the number of trays in rectifying, extractive, and stripping sections. ${ }^{13,14,57,58}$ However, the sensitivity analysis approach may not consider effects arising from correlated variables, and hence, is likely to fail to obtain the 
Table 1. Parameters for TAC Calculation

\begin{tabular}{lc}
\hline Parameters & Values \\
\hline Condensers & \\
Heat transfer coefficient & $0.852 \mathrm{~kW} /\left(\mathrm{K} \mathrm{m}^{2}\right)$ \\
Differential temperature & $28.8 \mathrm{~K}$ \\
Capital cost & $9367.8(\text { area in m })^{2}$ \\
Reboilers & $0.568 \mathrm{~kW} /\left(\mathrm{K} \mathrm{m}^{2}\right)$ \\
Heat transfer coefficient & $34.8 \mathrm{~K}$ \\
Differential temperature & $9367.8\left(\operatorname{area~in~} \mathrm{m}^{2}\right)^{0.65}$ \\
Capital cost & $((\mathrm{M} \& \mathrm{~S}) / 280) \bullet 101.9 \mathrm{D}^{1.066} \mathrm{~L}^{0.802}$ \\
Column vessel capital cost & $((\mathrm{M} \& \mathrm{~S}) / 280) \bullet 4.7 \mathrm{D}^{1.55} \mathrm{~L}$ \\
Tray capital cost & $7920\left(13.65 * Q_{\mathrm{r}}+0.4895^{*} Q_{\mathrm{c}}\right)$ \\
Energy cost & 3 years \\
Payback period &
\end{tabular}

optimal solution. Optimization techniques like linear programming, nonlinear programing (NLP), mixed-integer linear programming, and MINLP have been developed to overcome this drawback. 59

Before we present our proposed formulation, we first define all variables in the model. The variables for the extractive column are defined as follows: the entrainer flow rate is noted as $F_{\mathrm{E}}$, the reflux ratio is defined as $R_{1}, x_{\mathrm{A}, \mathrm{D} 1}$ as the purity of distillate $\mathrm{A}, x_{\mathrm{B}, \mathrm{W} 1}$ as the bottom impurity of $\mathrm{B}$ in the extractive column, total number of stages is represented by $N_{\text {ext }}$, mixture feed stage is $N_{\mathrm{FF}}$, entrainer feed stage is denoted as $N_{\mathrm{FE}}, Q_{\mathrm{r} 1}$ and $Q_{\mathrm{c} 1}$ are defined as heat duty of the reboiler and condenser, respectively. The variables for the entrainer regeneration column are defined as follows: the reflux ratio is denoted as $R_{2}$, total number of stages is defined as $N_{\text {reg }}$, entrainer feed stage is $N_{\mathrm{R}}, x_{\mathrm{B}, \mathrm{D} 2}$ and $x_{\mathrm{E}, \mathrm{W} 2}$ are used to denote the purity of distillate $\mathrm{B}$ and bottom purity of entrainer $\mathrm{E}$ in the entrainer regeneration column, $Q_{\mathrm{r} 2}$ and $Q_{\mathrm{c} 2}$ represent heat duty of the regeneration column, respectively. First of all, the purity of distillate A in the extractive column must satisfy some minimum purity requirement (denoted as minA_D1).

$$
x_{A, D 1} \geq \min A \_D 1
$$

Similarly, the bottom impurity of component B must not exceed some requirement (maxB_W1)

$$
x_{B, W 1} \leq \max B_{-} W 1
$$

Similar constraints can be written in the entrainer regeneration column as follows,

$$
\begin{aligned}
& x_{B, D 2} \geq \min B \_D 2 \\
& x_{E, W 2} \geq \min E_{-} W 2
\end{aligned}
$$

where minB_D2 and minE_W2 are the minimum requirements for the purities of components $\mathrm{B}$ and $\mathrm{E}$ in entrainer regeneration column.

The lower and upper bounds for the operational continuous variables are given as follows,

$$
\begin{aligned}
& \min R_{1} \leq R_{1} \leq \max R_{1} \\
& \min R_{2} \leq R_{2} \leq \max R_{2} \\
& \min \_F_{E} \leq F_{E} \leq \max \_F_{E}
\end{aligned}
$$

Since the process optimization are conducted through the SQP solver built in Aspen plus ${ }^{\circledR}$ process simulator, many other constraints (mass balance equations, equilibrium relations, enthalpy balance relations, etc.) are implicitly incorporated in Aspen plus ${ }^{\circledR}$ process simulator, which are not presented here.
Our objective is to minimize process energy consumption in the reboiler and condenser of both the extractive and regeneration columns, which is the same as that of You et al. ${ }^{15}$ We use OF to represent process energy consumption, which is calculated as follows

$$
\mathrm{OF}=\frac{Q_{\mathrm{r} 1}+m \cdot Q_{c 1}+Q_{\mathrm{r} 2}+m \cdot Q_{\mathrm{c} 2}}{F_{\mathrm{D} 1}+k \cdot F_{\mathrm{D} 2}}
$$

where $k$ represents product price factor; $m$ represents energy price difference factor for water in the condenser and heating fluid in the reboiler. Note that some other objective functions in the literature could also be used such as TAC, ${ }^{1,60}$ and heat duty ratio. ${ }^{57}$

The complete process optimization model named as CPOM is presented as follows

$$
(\mathbf{C P O M}) \text { Minimize } \mathrm{OF}=\frac{Q_{\mathrm{r} 1}+m \cdot Q_{\mathrm{c} 1}+Q_{\mathrm{r} 2}+m \cdot Q_{\mathrm{c} 2}}{F_{\mathrm{D} 1}+k \cdot F_{\mathrm{D} 2}}
$$

subject to: Eqs. 15-21 and other constraints implemented in Aspen plus ${ }^{\circledR}$ process simulator

We select top five entrainers from the ranking list. For each selected entrainer, the entire process optimization procedure can be described as follows, First, Aspen plus simulator builtin SQP method is used to solve model CPOM under a given column structure. The process is run with the RadFrac model in Aspen Plus in which the original UNIversal Functional Activity Coefficient (UNIFAC) model is used to calculate the activity coefficient in VLE. Second, a sensitivity analysis is performed to find optimal discrete values of the feed tray locations and total number of stages, while SQP is ran for each set of discrete variable values within bounds:

$$
\begin{aligned}
& \min \_N_{e x t} \leq N_{e x t} \leq \max N_{e x t} \\
& \min \_N_{F F} \leq N_{F F} \leq \max N_{F F} \\
& \min \_N_{F E} \leq N_{F E} \leq \max \_N_{F E} \\
& \min \_N_{r e g} \leq N_{r e g} \leq \max N_{r e g} \\
& \min \_N_{R F} \leq N_{R F} \leq \max N_{R F}
\end{aligned}
$$

The final optimization is found through minimizing $\mathrm{OF}$ value. Finally, the TAC is calculated to compare the separation sequences and evaluate selected entrainers. The TAC based on Douglas' cost formulas ${ }^{61}$ is defined as follows ${ }^{15,62}$

$$
\mathrm{TAC}=\frac{\text { capital cost }}{\text { payback period }}+\text { operating cost }
$$

where the capital cost includes the column shell cost, tray cost, condenser cost, and reboiler cost. The operating cost covers the energy cost in reboilers and condensers, the payback period is considered as 3 years, and Douglas's cost formulas are used with Marshall and Swift inflation 2011 index $(\mathrm{M} \& \mathrm{~S}=1518.1){ }^{63}$ All parameters used for TAC calculation are shown in Table 1.

\section{Results and Discussions}

We use the separation of acetone-chloroform (A-B) mixture as an example to illustrate the proposed design method. The acetone-chloroform (A-B) mixture forms a maximumboiling azeotrope at $x_{\text {azeo,Acetone }}=0.34, T=337.6 \mathrm{~K}$, and $P=1 \mathrm{~atm}$. In the literature, DMSO $\left(\mathrm{E}_{1}\right)$, chlorobenzene $\left(\mathrm{E}_{2}\right)$, EG $\left(\mathrm{E}_{3}\right), o$-xylene $\left(\mathrm{E}_{4}\right)$, and benzene $\left(\mathrm{E}_{5}\right)$ are five entrainers that have been proposed for conducting this separation. ${ }^{1}$ The 
Table 2. Singular Properties of Acetone-Chloroform Mixture with $\mathbf{E}_{\mathbf{1}}-\mathbf{E}_{\mathbf{5}}$

\begin{tabular}{lllllcll}
\hline & \multicolumn{3}{c}{ Azeotropes with $\mathrm{E}$} & & & & \\
\cline { 2 - 7 } & A-E & B-E & A-B-E & E & A & B & AZEO_AB \\
\hline Heavy entrainers $\left(\mathrm{E}_{1}-\mathrm{E}_{5}\right)$ & None & None & None & Stable & Unstable & Unstable & Saddle \\
\hline
\end{tabular}

acetone-chloroform (A-B) system with any of these five entrainers $\left(\mathrm{E}_{1}-\mathrm{E}_{5}\right)$ gives rise to a ternary mixture $\mathrm{A}-\mathrm{B}-\mathrm{E}$, which belongs to 1.0-2 class.

\section{Thermodynamic feasibility insight}

Following the proposed design method in Figure 2, we first conduct thermodynamic insight analysis for the process feasibility combining the analysis of residue curve maps and volatility order (i.e., 1.2).

The azeotropic behaviors of the acetone-chloroform (A-B) mixture with heavy entrainer DMSO $\left(\mathrm{E}_{1}\right)$, chlorobenzene $\left(\mathrm{E}_{2}\right)$, EG $\left(\mathrm{E}_{3}\right), o$-xylene $\left(\mathrm{E}_{4}\right)$, or benzene $\left(\mathrm{E}_{5}\right)$ are shown in Table 2. From Table 2, it can be observed that ternary mixtures A-B-E demonstrate the same singular properties and they all belong to the same 1.02 Serafimov's class with a reported occurrence of $8.5 \%$. $^{35}$

Figure 5 depicts the thermodynamic features for the ternary mixture acetone-chloroform-chlorobenzene. Similar principles can also be generated for the rest ternary mixtures including acetone-chloroform-DMSO, acetone-chloroform-EG, acetone-chloroform-Benzene, and acetone-chloroform- $O$ xylene. In Figure 5, the univolatility curve $\alpha_{\mathrm{AB}}=1$ reaches the binary side $\mathrm{B}-\mathrm{E}$ when using these heavy entrainers. Based on the feasibility analysis presented in Figure 3, both acetone and chloroform can be recovered as products. ${ }^{18,24}$ For each of the selected heavy entrainers, the univolatility curve $\alpha_{\mathrm{AB}}=1$ reaches the entrainer-chloroform edge. Therefore, there is no maximum entrainer flow rate to recover acetone which is our goal.

Laroche et al. ${ }^{23}$ acknowledged that the acetone-chloroform separation could be performed by azeotropic distillation as well in which the entrainer is directly added to the mixture because acetone and chloroform are both unstable nodes of the residue curve map. Lang et al. ${ }^{27,28}$ showed that it is better to use extractive distillation for the separation of acetone-chloroform (A-B) mixture rather than azeotropic distillation because the entrainer feed generates an extractive separatrix that is also curved and closer to the B-E side than the RCM stable separatrix, thus increasing the feasible region in which $\mathrm{A}$ is the unstable node. In a brief, the extractive distillation improves the recovery yield of component $\mathrm{A}$ as the first distillate cut. ${ }^{18,19,27,28}$

\section{Results from entrainer property analysis}

Physicochemical properties of acetone-chloroform (A-B) mixture such as molecular weight (MWs), boiling point $\left(T_{\mathrm{b}}\right)$, and melting point $\left(T_{\mathrm{m}}\right)$ are given in Table 3 . The saturated vapor pressure for acetone-chloroform azeotrope is calculated using the correlation given below

$$
\ln P=a+b / T+c \cdot \ln T+d \cdot T^{e}
$$

where the values for $T, a, b, c, d$, and $e$ are presented in Table 3. The results for saturated vapor pressure are also given in Table 3. From Table 3, it can be observed that acetone and chloroform have very close saturated vapor pressure and boiling point.

The original UNIFAC model is used to compute activity coefficients of VLE evaluate the five thermodynamic properties at atmospheric pressure that we selected. The results are presented in Table 4. From Table 4, it is observed that the five entrainers have rather different values of these properties which will translate into different total score that are now discussed.

\section{Results from entrainer evaluation and ranking through fuzzy logic}

We use the proposed membership functions (i.e., Eqs. 5-10) to calculate property attribute values and total scores for $\mathrm{E}_{1}-$ $E_{5}$. The weighting factor values assigned for $E_{1}-E_{5}$ from Eqs. 13 and 14 are given as follows,
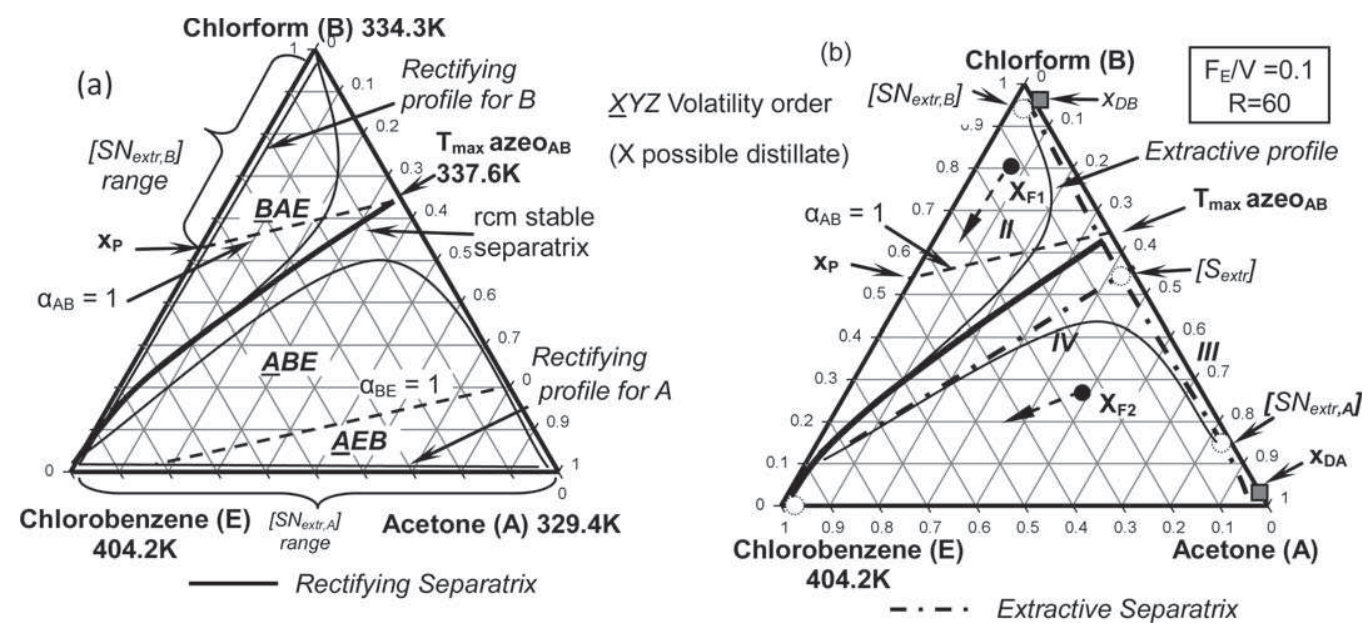

Figure 5. Thermodynamic principles for 1.0-2 case with chlorobenzene. 
Table 3. Physicochemical Characteristics of Acetone-Chloroform Mixture

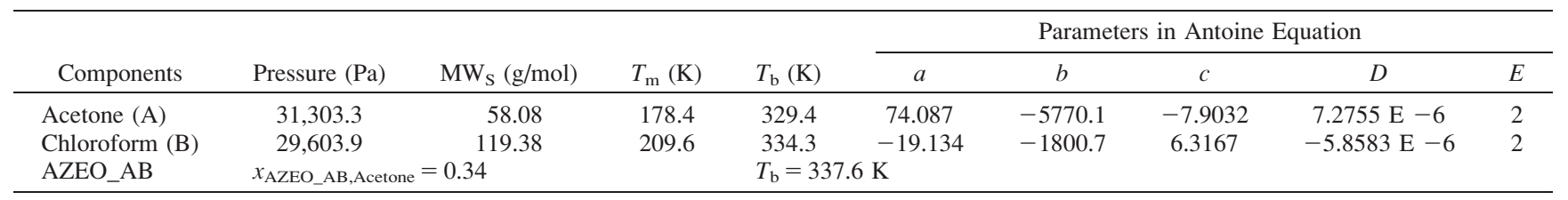

Table 4. Activity Coefficients and Five Thermodynamic Properties for $E_{1}-E_{5}$

\begin{tabular}{|c|c|c|c|c|c|c|c|c|}
\hline Entrainers & CAS Num & $\gamma_{\mathrm{A}, \mathrm{S}}^{\infty}$ & $\gamma_{\mathrm{B}, \mathrm{S}}^{\infty}$ & $\alpha_{\mathrm{A}, \mathrm{B}}$ & $S_{\mathrm{P}}$ & $\mathrm{MW}_{\mathrm{S}}$ & $T_{\mathrm{b}}(\mathrm{K})$ & $T_{\mathrm{m}}(\mathrm{K})$ \\
\hline DMSO $\left(E_{1}\right)$ & $67-68-5$ & 1.5681 & 0.6279 & 2.6409 & 0.4741 & 78.13 & 463.89 & 292.15 \\
\hline Chlorobenzene $\left(\mathrm{E}_{2}\right)$ & $108-90-7$ & 1.2300 & 1.0382 & 1.2527 & 0.4195 & 112.56 & 404.15 & 228.15 \\
\hline $\mathrm{EG}\left(\mathrm{E}_{3}\right)$ & $107-21-1$ & 3.7352 & 1.0548 & 3.7445 & 0.2505 & 62.07 & 470.45 & 260.25 \\
\hline$o$-Xylene $\left(\mathrm{E}_{4}\right)$ & $95-47-6$ & 1.2712 & 0.7513 & 1.7891 & 0.4304 & 106.16 & 417.15 & 248.15 \\
\hline Benzene $\left(E_{5}\right)$ & $71-43-2$ & 1.4454 & 0.8411 & 1.8171 & 0.4177 & 78.11 & 353.25 & 278.65 \\
\hline
\end{tabular}

$\mathbf{W}=\left\{w_{1}, w_{2}, w_{3}, w_{4}, w_{5}\right\}=\left\{\begin{array}{llll}0.4, & 0.35,0.05, & 0.15,0.05\end{array}\right.$

Note that the assignment in Eq. 30 reflects that relative volatility, solubility power, and boiling point are considered as the main selection criteria to screening entrainers based on computer-aided molecular design (CAMD) approaches for an extractive distillation process. ${ }^{13,40,46}$

To validate the rationality of assigned weighting factor values that should meet the requirement in Eqs. 13 and 14, a sensitive study is conducted using five scenarios with different assigned weight factors. Table 5 gives the weighting factor values for each scenario. Consequently, the total scores of $E_{1}-$ $\mathrm{E}_{5}$ for each scenario are obtained in Table 6. Although we change the assigned weighting factor values, resulting in a little bit change of total scores for $\mathrm{E}_{1}-\mathrm{E}_{5}$, the same ranking is obtained. In other words, if the assigned weight factors change a little bit and satisfy the conditions in Eqs. 13 and 14, the ranking for $E_{1}-E_{5}$ will not change. The possible reason is that the attribute values for those five properties of $E_{1}-E_{5}$ are distributed between 0 and 1, which are small values. The total scores for $E_{1}-E_{5}$ do not change significantly with those small attribute values when changing assigned weighting factor values within a reasonable region restricted by Eqs. 13 and 14 .

The computational results are presented in Table 7. As it can be seen from Tables 4 and 7, EG $\left(\mathrm{E}_{3}\right)$ has the highest rela-

Table 5. The Values of Weight Factors for $E_{1}-E_{5}$ in Five Scenarios

\begin{tabular}{lccccc}
\hline Cases & W1 & W2 & W3 & W4 & W5 \\
\hline 1 & 0.40 & 0.35 & 0.05 & 0.15 & 0.05 \\
2 & 0.30 & 0.30 & 0.15 & 0.15 & 0.10 \\
3 & 0.30 & 0.40 & 0.05 & 0.15 & 0.10 \\
4 & 0.40 & 0.40 & 0.00 & 0.15 & 0.05 \\
5 & 0.30 & 0.35 & 0.10 & 0.15 & 0.10 \\
\hline
\end{tabular}

tive volatility $\left(\alpha_{\mathrm{A}, \mathrm{B}}^{\infty}\right)$ and gets by far the highest attribute value $\mu\left(\alpha_{\mathrm{A}, \mathrm{B}}^{\infty}\right)$ for that property which reaches 0.9606 . Conversely, the attribute value for the solubility power $\left(S_{\mathrm{P}}\right)$ and the boiling points are the smallest. Hence, the total score for EG $\left(E_{3}\right)$ reaches 0.5556. It remains the highest value of all five entrainers because of the highest weight factor is assigned for relative volatility in total score calculation. For DMSO $\left(\mathrm{E}_{1}\right)$ that has the second best attribute value $\mu\left(\alpha_{\mathrm{A}, \mathrm{B}}^{\infty}\right)$ and the best attribute value $\mu\left(S_{\mathrm{P}}\right)$, the total score reaches 0.5229 because the attribute values for boiling point and melting points are low. Finally, we observe that the lowest total score is 0.3621 for benzene, closely followed by 0.3918 for chlorobenzene due to the fact that benzene boiling point is too low and the relative volatility attribute is low whereas chlorobenzene has a very low attribute value for the relative volatility. The total scores of $\mathrm{E}_{1}-\mathrm{E}_{5}$ are ranked in the following order: EG $>$ DMSO $>o$-xylene $>$ chlorobenzene $>$ benzene.

\section{Process optimization}

In this part, we run an optimization based on the total energy consumption per distillate product of the process including both the extractive distillation column and the entrainer regeneration column for each five entrainers. We rank them according to the TAC of each process and compare them the ranking proposed by the fuzzy logic-based total score. The operating conditions are kept constant for all entrainers and are given in Table 8 . Starting from a $100 \mathrm{kmol} /$ $\mathrm{h}$ equimolar feed acetone-chloroform, the distillate flow rate form both columns are fixed to $50 \mathrm{kmol} / \mathrm{h}$ with at least 0.995 purity. Both columns operate at 1.1 atm with no pressure drop. Feed temperature for the extractive column is set equal to $320 \mathrm{~K}$, whereas the regeneration column is fed at boiling point by the bottom stream of the extractive column. The lower and upper bounds of the operating variables are estimated using the sensitivity analysis, and the results are given in Table 9.

Table 6. Total Scores of $E_{1}-E_{5}$ in Five Scenarios

\begin{tabular}{lccccc}
\hline Cases & DMSO $\left(\mathrm{E}_{1}\right)$ & Chlorobenzene $\left(\mathrm{E}_{2}\right)$ & EG $\left(\mathrm{E}_{3}\right)$ & $o$-Xylene $\left(\mathrm{E}_{4}\right)$ & Benzene $\left(\mathrm{E}_{5}\right)$ \\
\hline 1 & 0.52290 & 0.39180 & 0.55560 & 0.44850 & 0.36210 \\
2 & 0.50765 & 0.46000 & 0.56397 & 0.50228 & 0.41854 \\
3 & 0.51608 & 0.46146 & 0.52060 & 0.50316 & 0.40531 \\
4 & 0.52713 & 0.39249 & 0.53390 & 0.44895 & 0.35551 \\
5 & 0.51186 & 0.46073 & 0.54228 & 0.50273 & 0.41192 \\
\hline
\end{tabular}


Table 7. Attribute Values and Total Scores for $\mathbf{E}_{\mathbf{1}}-\mathbf{E}_{\mathbf{5}}$

\begin{tabular}{lccccc}
\hline Entrainers & $\mu\left(\alpha_{\mathrm{A}, \mathrm{B}}\right)$ & $\mu\left(S_{\mathrm{P}}\right)$ & $\mu\left(\mathrm{MW}_{\mathrm{S}}\right)$ & $\mu\left(T_{\mathrm{b}}\right)$ & $\mu\left(T_{\mathrm{m}}\right)$ \\
\hline DMSO $\left(\mathrm{E}_{1}\right)$ & 0.5743 & 0.6502 & 0.5659 & 0.1283 & 0.3617 \\
Chlorobenzene $\left(\mathrm{E}_{2}\right)$ & 0.0758 & 0.5456 & 0.5310 & 0.6262 & 1.0000 \\
EG $\left(\mathrm{E}_{3}\right)$ & 0.9606 & 0.2215 & 0.6552 & 0.0737 & 0.5229 \\
o-Xylene $\left(\mathrm{E}_{4}\right)$ & 0.2367 & 0.5665 & 0.5577 & 0.5178 & 0.3918 \\
Benzene $\left(\mathrm{E}_{5}\right)$ & 0.2451 & 0.5422 & 0.6745 & 0.0000 & 0.0000 \\
\hline
\end{tabular}

Table 8. Operating Conditions for Process Optimization

\begin{tabular}{lcc}
\hline Specifications & $\begin{array}{c}\text { Extractive } \\
\text { Column }\end{array}$ & $\begin{array}{c}\text { Regeneration } \\
\text { Column }\end{array}$ \\
\hline Feed flow rate $(\mathrm{kmol} / \mathrm{h})$ & 100 & - \\
Distillate flow rate $(\mathrm{kmol} / \mathrm{h})$ & 50 & 50 \\
Column pressure $(\mathrm{atm})$ & 1.1 & 1.1 \\
Feed temperature $(\mathrm{K})$ & 320 & 320 \\
Main feed composition & & - \\
$x_{\mathrm{A}}$, mole fraction & 0.5 & - \\
$x_{\mathrm{B}}$, mole fraction & 0.5 & - \\
$x_{\mathrm{E}}$, mole fraction & 0 & - \\
Entrainer composition & & \\
$x_{\mathrm{A}}$, mole fraction & 0 & \\
$x_{\mathrm{B}}$, mole fraction & 0 & \\
$x_{\mathrm{E}}$, mole fraction & 1 & \\
Controlled variables constraint & & \\
Top product & $\geq 0.995$ acetone $\geq 0.995$ chloroform \\
Bottom product & $\leq 0.001$ acetone $\geq 0.9999$ entrainer \\
\hline
\end{tabular}

During optimization process, it is observed that for each case, there is a nonmonotonic effect on each manipulated variable as was acknowledged by many authors. ${ }^{1,12}$ For instance, $R_{1}, R_{2}$, and entrainer feed flow rate will be affected by the feed stages $N_{\mathrm{FF}}, N_{\mathrm{FE}}$ and $N_{\mathrm{RF}}$. For a given entrainer flow rate, there is an optimal reflux ratio $R_{1}$ that yields the maximum acetone purity. The higher the entrainer flow rate, the higher the acetone purity can be obtained but then the OF and TAC figures also increase. The impurities of chloroform and entrainer are affected by the entrainer flow rate and reflux ratio $R_{1}$. Increasing the entrainer feed flow rate decreases the chloroform impurity but increases the entrainer impurity.

The final optimization results for $\mathrm{E}_{1}-\mathrm{E}_{5}$ are given in Table 10. Figure 6 explicitly illustrates total scores and optimal TAC values for $\mathrm{E}_{1}-\mathrm{E}_{5}$.

From Table 10 and Figure 6, we observe that the process TAC for the separation of the acetone-chloroform mixture with $\mathrm{E}_{1}-\mathrm{E}_{5}$ are ranked as $\mathrm{E}_{3}(\mathrm{EG})<\mathrm{E}_{1}(\mathrm{DMSO})<\mathrm{E}_{4}(o-$ xylene) $<\mathrm{E}_{2}$ (chlorobenzene) $<\mathrm{E}_{5}$ (benzene). Furthermore, this is consistent with the total score ranking based on thermodynamic properties of the entrainers and mixture A-B.

The TAC value of $\$ 630,000$ using $\mathrm{E}_{1}$ (DMSO) and $\$ 610,000$ using $E_{3}(E G)$ is much smaller that the TAC for the three other entrainer candidates. The process with DMSO supremacy verifies the recommendation of Luyben to choose that entrainer to achieve 0.995 pure products with the same main feed and distillate flow rates. ${ }^{32}$ The DMSO design figures are very close to those reported by Luyben ${ }^{32}$ thus validating our design.

It is worth mentioning that Luyben ${ }^{1}$ concluded that EG, chlorobenzene, and $o$-xylene are not suitable to separate the acetone-chloroform mixture with the desired separation specifications. From Table 10, we show that all entrainers can achieve the separation with the purity targeted by Luyben. ${ }^{1} \mathrm{E}_{3}$ (EG) is a very good candidate as the process TAC is similar to DMSO's one. Indeed, EG $\left(\mathrm{E}_{3}\right)$ allows one to use the lowest reflux ratio $(0.203$ for extractive column and 0.369 for regeneration column). This is typically related to the fact that the relative volatility of EG is the largest one among $\mathrm{E}_{1}-\mathrm{E}_{5}$ (Table 4). However, the entrainer feed flow rate is the lowest for DMSO (i.e., $164.9 \mathrm{kmol} / \mathrm{h}$ ) followed by the value with EG (i.e., $221.5 \mathrm{kmol} / \mathrm{h}$ ). The possible reason is that DMSO has a much higher solution power value than others, which leads to a lower feed flow rate of DMSO. From Table 10, it can also be observed that the duties for condensers and reboilers in the extractive distillation column and in the regeneration column are slightly lower for EG than for DMSO and are much smaller than for the other entrainers (i.e., $E_{2}, E_{4}-E_{5}$ ). These results are correlated to the reflux ratio values and the entrainer feed flow rate: DMSO with the lowest entrainer flow rate requires almost the same boiler duty with that of EG because the separation requires a higher reflux ratio for DMSO than for EG.

Similarly the heat duty for $\mathrm{E}_{2}$ (chlorobenzene) is very large because the $E_{2}$ feed flow rate of $1659.2 \mathrm{kmol} / \mathrm{h}$ to the extractive column entrainer flow rate is by far the greatest of all entrainers and a large reflux ratio of 9.803 for the regeneration

Table 9. Lower and Upper Bounds of Operating Variables During Process Optimization

\begin{tabular}{lcc}
\hline Operating Variables & Lower Limit & Upper Limit \\
\hline Extractive column & & \\
Total number of stage, $N_{\text {ext }}$ & 15 & 50 \\
Feed tray, $N_{\mathrm{FF}}$ & 9 & 50 \\
Entrainer feed tray, $N_{\mathrm{FE}}$ & 3 & 25 \\
$\quad$ Reflux ratio, $R_{1}$ & 0.2 & 15 \\
$\quad$ Entrainer feed $(\mathrm{kmol} / \mathrm{h}), F_{\mathrm{E}}$ & 40 & 350 \\
Regeneration column & & \\
Total number of stage, $N_{\text {reg }}$ & 10 & 54 \\
Feed tray, $N_{\mathrm{RF}}$ & 3 & 30 \\
Reflux ratio, $R_{2}$ & 0.3 & 30 \\
\hline
\end{tabular}

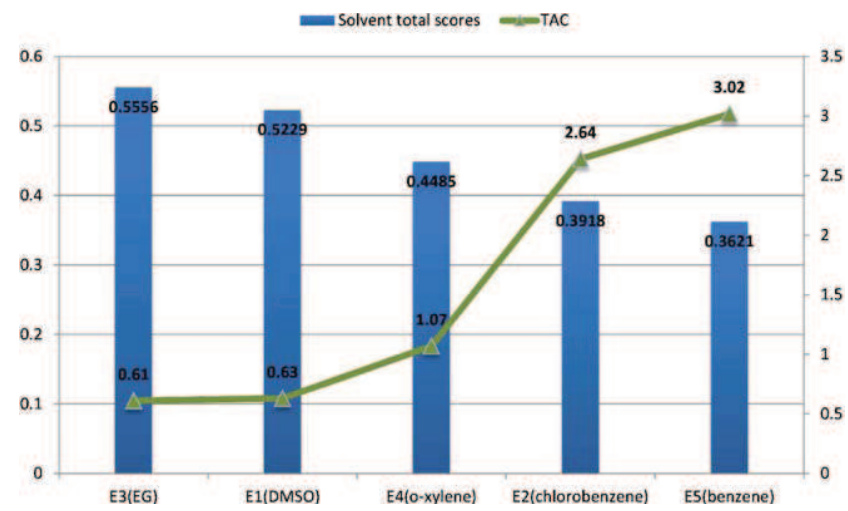

Figure 6. Total scores and TAC values for $E_{1}-E_{5}$.

[Color figure can be viewed in the online issue, which is available at wileyonlinelibrary.com.] 
Table 10. Comparison of Optimal Design Results with $\mathbf{E}_{\mathbf{1}}-\mathbf{E}_{\mathbf{5}}$

\begin{tabular}{|c|c|c|c|c|c|}
\hline & $\begin{array}{c}\text { DMSO } \\
\mathrm{E}_{1} \\
\end{array}$ & $\begin{array}{c}\text { Chlorobenzene } \\
\mathrm{E}_{2} \\
\end{array}$ & $\begin{array}{l}\mathrm{EG} \\
\mathrm{E}_{3} \\
\end{array}$ & $\begin{array}{c}o \text {-Xylene } \\
\mathrm{E}_{4}\end{array}$ & $\begin{array}{c}\text { Benzene } \\
\mathrm{E}_{5}\end{array}$ \\
\hline \multicolumn{6}{|l|}{ Extractive column } \\
\hline Total number of stage, $N_{\text {ext }}$ & 23 & 45 & 30 & 37 & 44 \\
\hline Feed tray, $N_{\mathrm{FF}}$ & 11 & 14 & 9 & 17 & 21 \\
\hline Entrainer feed tray, $N_{\mathrm{FE}}$ & 4 & 9 & 3 & 5 & 20 \\
\hline Reflux ratio, $R_{1}$ & 0.899 & 5.350 & 0.203 & 1.225 & 10.247 \\
\hline Entrainer feed $(\mathrm{kmol} / \mathrm{h}), F_{\mathrm{E}}$ & 164.9 & 1659.2 & 221.5 & 354.9 & 270.7 \\
\hline $\operatorname{Ar}\left(\mathrm{m}^{2}\right)$ & 78.4 & 458.6 & 72.8 & 141.1 & 255.99 \\
\hline Ac $\left(\mathrm{m}^{2}\right)$ & 65.5 & 105.8 & 22.6 & 76.8 & 187.06 \\
\hline Column diameter $(\mathrm{m})$ & 1.01 & 3.09 & 0.869 & 1.51 & 2.09 \\
\hline Tray capital cost $\left(10^{6} \$\right)$ & 0.018 & 0.209 & 0.019 & 0.056 & 0.112 \\
\hline Vessel capital cost $\left(10^{6} \$\right)$ & 0.169 & 1.010 & 0.183 & 0.398 & 0.653 \\
\hline Condenser and reboiler cost $\left(10^{6} \$\right)$ & 0.302 & 0.697 & 0.223 & 0.391 & 0.625 \\
\hline Condenser duty(MW) & 0.776 & 2.596 & 0.497 & 0.910 & 4.59 \\
\hline Reboiler duty(MW) & 1.550 & 9.065 & 1.438 & 2.789 & 5.06 \\
\hline \multicolumn{6}{|l|}{ Regeneration column } \\
\hline Total number of stage, $N_{\text {reg }}$ & 12 & 33 & 10 & 16 & 43 \\
\hline Reflux ratio, $R_{2}$ & 0.756 & 9.803 & 0.369 & 2.413 & 26.100 \\
\hline $\operatorname{Ar}\left(m^{2}\right)$ & 56.7 & 220.2 & 64.9 & 88.9 & 559.03 \\
\hline $\operatorname{Ac}\left(\mathrm{m}^{2}\right)$ & 61.0 & 138.8 & 21.5 & 117.6 & 381.54 \\
\hline Column diameter $(\mathrm{m})$ & 0.83 & 2.35 & 0.780 & 1.34 & 3.16 \\
\hline Tray capital cost $\left(10^{6} \$\right)$ & 0.006 & 0.098 & 0.004 & 0.018 & 0.207 \\
\hline Vessel capital cost $\left(10^{6} \$\right)$ & 0.072 & 0.575 & 0.056 & 0.162 & 0.995 \\
\hline Condenser and reboiler cost $\left(10^{6} \$\right)$ & 0.265 & 0.544 & 0.210 & 0.381 & 1.018 \\
\hline Condenser duty(MW) & 0.723 & 4.010 & 0.565 & 1.393 & 11.02 \\
\hline Reboiler duty(MW) & 1.12 & 4.353 & 1.283 & 1.757 & 11.05 \\
\hline \multicolumn{6}{|l|}{ Heat exchanger, HX1 } \\
\hline Exchanger duty (MW) & 1.080 & 6.720 & 1.583 & 2.156 & 0.399 \\
\hline TAC $\left(10^{6} \$ /\right.$ year $)$ & 0.63 & 2.64 & 0.61 & 1.07 & 3.02 \\
\hline
\end{tabular}

column is needed to achieve the target product specifications. This is because the acetone-chlorobenzene system does not have a large relative volatility (i.e., 1.2527 in Table 4), which leads to difficulty in attaining the desired acetone purity.

When $\mathrm{E}_{5}$ (benzene) is used as the entrainer, a large reflux ratio (i.e., 26.1) of the regeneration column is needed as the boiling point of benzene is closest to that of chloroform among $\mathrm{E}_{1}-\mathrm{E}_{5}$. Notice that for benzene the entrainer feed and main feed trays locations are one tray apart. Typically, this indicates that the azeotropic distillation process, also feasible, is likely a better design than the extractive distillation process. The inherent problem of using benzene as the entrainer should be related to the ease of attaining higher purity levels in extractive distillation with DMSO as entrainer with only modest increases in $R$ and entrainer flow.

Based on the above discussion, one can conclude that DMSO $\left(E_{1}\right)$ and EG $\left(E_{3}\right)$ are the two best entrainers for the

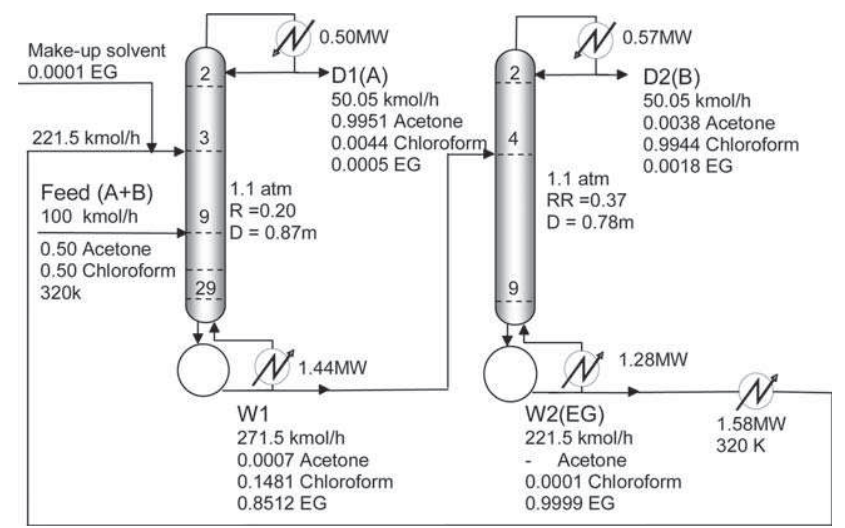

Figure 7. Optimal design of steady-state two-column extractive distillation process using EG. separation of acetone-chloroform system. The optimal design of the two-column extractive distillation process for DMSO is similar to the one published by Luyben. ${ }^{24}$ The one with EG $\left(E_{3}\right)$ is illustrated in Figure 7. The liquid composition and temperature profiles in the extractive column and the regeneration column with EG $\left(\mathrm{E}_{3}\right)$ are given in Figure 8. It is noticed that the goal of the extractive section is fulfilled in preventing the entrainer EG $\left(\mathrm{E}_{3}\right)$ from going significantly into the rectifying section. With high attribute value of entrainer evaluated through fuzzy logic, only very small value of reflux ratios are required for both extractive and regeneration columns. From Figures $8 \mathrm{a}$, c, the flat composition profiles cannot be generated. Hence, a large number of stages for each section are required to achieve the specified targets.

\section{Conclusions}

In this article, we proposed a systematic approach to the design of an extractive distillation for the separation of maximum-boiling azeotropes with heavy entrainers, considering also the entrainer regeneration column. The proposed method was illustrated using the separation of acetone/chloroform azeotropes with five heavy entrainers (DMSO, chlorobenzene, EG, $o$-xylene, and benzene). The thermodynamic insights suggested that (1) acetone-chloroform (A-B) mixture with all those heavy entrainers $\mathrm{E}$ belong to the same 1.0-2 Serafimov's class ternary diagram; (2) acetone is chosen as a distillate product with a larger feasible region than that of chloroform as the extractive separatrix is curved and closer to the B-E side than the RCM stable separatrix. (iii) a prescreening of the entrainer performance can be made and the ranking obtained is confirmed by the optimization of the full process. The prescreening uses fuzzy logic attribute values related to properties: the relative volatility under infinite dilution, the 

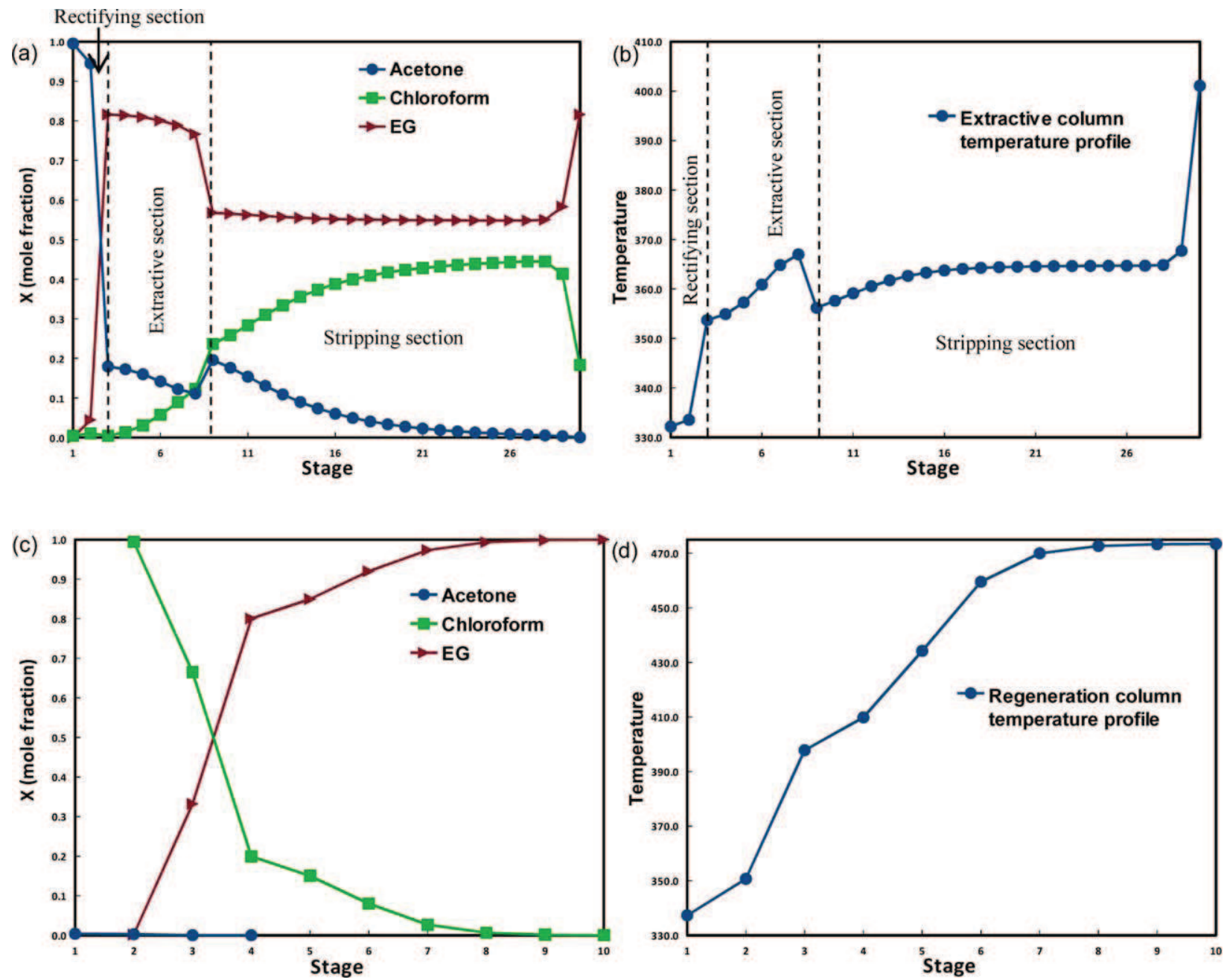

Figure 8. Liquid composition and temperature profiles for acetone-chloroform mixture with EG ( $\left.E_{3}\right)$.

(a) Liquid composition profiles in the extractive column; (b) Temperature profile in the extractive column; (c) Liquid composition profiles in the regeneration column; (d) Temperature profiles in the regeneration column. [Color figure can be viewed in the online issue, which is available at wileyonlinelibrary.com.]

solubility power of the entrainer vs. the product, the entrainer molecular weight and boiling and melting points. The optimized results are discussed in relation with the properties to explain the correlation between the entrainer prescreening ranking and the key operating parameters that correspond to an optimal design.

Both the prescreening ranking and the optimized process results demonstrated that EG and DMSO are the best entrainers for the separation of acetone-chloroform system using extractive distillation followed by $o$-xylene, chlorobenzene, and benzene. Finally, optimal design of steady-state two-column extractive distillation process using EG are presented.

The proposed method can incorporate additional properties such as phase stability and sustainability-related properties for entrainer screening. It can also be extended to screening more potential entrainer candidates for other ternary Serafimov's classes using CAMD.

\section{Acknowledgments}

This work is financially supported by the National Natural Science Foundation of China (21206174, 21176270).

\section{Notation}

\section{Variables}

$F_{\mathrm{E}}=$ entrainer flow rate, $\mathrm{kmol} / \mathrm{h}$

$K=$ vapor-liquid equilibrium distribution constant

$\mathrm{MW}=$ molecular weight, $\mathrm{g} / \mathrm{mol}$

$N_{\text {ext }}=$ total number of stages of extractive column

$N_{\mathrm{FF}}=$ mixture feed stage in extractive column

$N_{\mathrm{FE}}=$ entrainer feed stage in extractive column

$N_{\text {reg }}=$ total number of stages of regeneration column

$N_{\mathrm{RF}}=$ feed stage in regeneration column

$P=$ pressure, $\mathrm{kPa}$

$P^{\circ}=$ saturated vapor pressure, $\mathrm{kPa}$

$Q_{\mathrm{c}}=$ heat duty of the condenser, MW

$O_{\mathrm{r}}=$ heat duty of the reboiler, MW

$R=$ reflux ratio

$S_{\mathrm{P}}=$ solubility power

$T_{\mathrm{b}}=$ boiling temperature, $\mathrm{K}$

$T_{\text {score }}=$ total score indicator

$T_{\mathrm{m}}=$ melting temperature, $\mathrm{K}$

$U=$ entrainer evaluation set

$W=$ weight factor

$k=$ product price factor

$m=$ energy price difference factor

$x=$ mole fraction in liquid phase

$x_{\mathrm{A}, \mathrm{D}}=$ distillate purity of $\mathrm{A}$, mole fraction

$x_{\mathrm{B}, \mathrm{W}}=$ bottom impurity of $\mathrm{B}$, mole fraction

$x_{\mathrm{B}, \mathrm{D}}=$ distillate purity of $\mathrm{B}$, mole fraction

$x_{\mathrm{E}, \mathrm{W}}=$ bottom purity of entrainer, mole fraction 
$y=$ mole fraction in vapor phase

$\alpha=$ relative volatility

$\gamma=$ activity coefficient

$\gamma^{\infty}=$ activity coefficient at infinite dilution

$\mu_{\mathrm{A}}(\mathrm{X})=$ membership function

\section{Abbreviations}

$\mathrm{A}=$ lower boiling point component in azeotropic mixtures

$\mathrm{B}=$ higher boiling point component in azeotropic mixtures

$\mathrm{CAMD}=$ computer-aided molecular design

CPOM = complete process optimization model

DMSO $=$ dimethylsulfoxid

$\mathrm{E}=$ entrainer

$\mathrm{EG}=$ ethylene glycol

HX1 = heater exchanger for entrainer recycle stream

MILNP $=$ mixed-integer nonlinear programming

$\mathrm{NLP}=$ nonlinear programing

$\mathrm{OF}=$ objective function

SQP = Sequential Quadratic Programming

$\mathrm{TAC}=$ total annualized cost

maxB_W1 $=$ maximum impurity requirement of B at bottom of extractive column

$\max \_F_{\mathrm{E}}=$ the upper limit of entrainer flow rate, $\mathrm{kmol} / \mathrm{h}$

$\max \_N_{\text {ext }}=$ the upper limit of total number of stages of extractive column

$\max \_N_{\mathrm{FF}}=$ the upper limit of mixture feed stage

$\max \_N_{\mathrm{FE}}=$ the upper limit of entrainer feed stage

$\max \_N_{\text {reg }}=$ the upper limit of total number of stages of regeneration column

$\max \_N_{\mathrm{RF}}=$ the upper limit of feed stage in regeneration column

$\min \_F_{\mathrm{E}}=$ the lower limit of entrainer flow rate, $\mathrm{kmol} / \mathrm{h}$

$\min \_N_{\text {ext }}=$ the lower limit of total number of stages of extractive column

$\min \_N_{\mathrm{FF}}=$ the lower limit of mixture feed stage

$\min \_N_{\mathrm{FE}}=$ the lower limit of entrainer feed stage

min $\_N_{\text {reg }}=$ the lower limit of total number of stages of regeneration column

$\min \_N_{\mathrm{RF}}=$ the lower limit of feed stage in regeneration column

minA_D1 $=$ minimum purity requirement of $\mathrm{A}$ at top of extractive column

minB_D2 $=$ minimum purity requirement of $\mathrm{B}$ at top of regeneration column

minE_W2 $=$ minimum purity requirement of $\mathrm{E}$ at top of regeneration column

$\mathrm{RCM}=$ residu curve map

VLE $=$ vapor-liquid equilibrium

\section{Literature Cited}

1. Luyben WL, Chien IL. Design and Control of Distillation Systems for Separating Azeotropes, London: Wiley Online Library, 2010.

2. Bernot C, Doherty MF, Malone MF. Patterns of composition change in multicomponent batch distillation. Chem Eng Sci. 1990;45(5): 1207-1221.

3. Knapp JP, Doherty MF. A new pressure-swing-distillation process for separating homogeneous azeotropic mixtures. Ind Chem Eng Res. 1992;31(1):346-357.

4. Phimister JR, Seider WD. Semicontinuous, pressure-swing distillation. Ind Chem Eng Res. 2000;39(1):122-130.

5. Modla G, Lang P. Feasibility of new pressure-swing batch distillation methods. Chem Eng Sci. 2008;63(11):2856-2874.

6. Luyben W. Comparison of extractive distillation and pressure-swing distillation for acetone/chloroform separation. Comput Chem Eng. 2013;50:1-7.

7. Doherty MF, Malone MF. Conceptual Design of Distillation Systems, New York: McGraw-Hill, 2001.

8. Lladosa E, Montón J B, Cruz Burguet M. Separation of di-npropyl ether and n-propyl alcohol by extractive distillation and pressure swing distillation: computer simulation and economic optimization. Chem Eng Proc. 2011;50:1266-1274.

9. Modla G, Lang P. Removal and recovery of organic solvents from aqueous waste mixtures by extractive and pressure swing distillation. Ind Eng Chem Res. 2012;51:11473-11481

10. Munoz R, Monton JB, Burguet MC, De la Torre J. Separation of isobutyl alcohol and isobutyl acetate by extractive distillation and pressure-swing distillation: simulation and optimization. Sep Purif Technol. 2006;50:175-183.
11. Lee FM, Pahl RH. Entrainer screening study and conceptual extractive distillation process to produce anhydrous ethanol from fermentation broth. Ind Eng Chem Process Des Dev. 1985;24(1):168-172.

12. Knapp JP, Doherty MF. Minimum entrainer flow for extractive distillation: a bifurcation theoretic approach. AIChE J. 1994;40(2):243268.

13. Kossack S, Kraemer K, Gani R, Marquardt W. A systematic synthesis framework for extractive distillation processes. Chem Eng Res. 2008;86(7):781-792.

14. Luyben W. Effect of entrainer on controllability in extractive distillation. Ind Chem Eng Res. 2008;47(13):4425-4439.

15. You X, Rodriguez-Donis I, Gerbaud V. Improved design and efficiency of the extractive distillation process for acetone-methanol with water. Ind Eng Chem Res. 2015;54:491-501.

16. Wahnschafft OM, Westerberg AW. The product composition regions of azeotropic distillation columns: II. Separability in two-feed columns and entrainer selection. Ind Eng Chem Res. 1993;32(6):11081120 .

17. Thomas B, Karl Hans S. Knowledge integrating system for the selection of entrainers for extractive and azeotropic distillation. Comput Chem Eng. 1994;18(Suppl.1):25-29.

18. Rodríguez-Donis I, Gerbaud V, Joulia X. Thermodynamic insights on the feasibility of homogeneous batch extractive distillation. 1. Azeotropic mixtures with heavy entrainer. Ind Chem Eng Res. 2009; 48(7):3544-3559.

19. Rodríguez-Donis I, Gerbaud V, Joulia X. Thermodynamic insights on the feasibility of homogeneous batch extractive distillation, 2. Low-relative-volatility binary mixtures with a heavy entrainer. Ind Chem Eng Res. 2009;48(7):3560-3572.

20. Rodríguez-Donis I, Gerbaud V, Joulia X. Thermodynamic insight on extractive distillation with entrainer forming new azeotropes. In: Proceedings of Distillation \& Absorption, Eindhoven, Holland, September $12-15,2010 ; 431-436$.

21. Rodríguez-Donis I, erbaud V, Joulia X. Thermodynamic insights on the feasibility of homogeneous batch extractive distillation, 3. Azeotropic mixtures with light boiling entrainer. Ind Chem Eng Res. 2012;51(2):4643-4660.

22. Rodríguez-Donis I, Gerbaud V, Joulia X. Thermodynamic insights on the feasibility of homogeneous batch extractive distillation, 4. Azeotropic mixtures with intermediate boiling entrainer. Ind Chem Eng Res. 2012;51(18):6489-6501.

23. Laroche L, Bekiaris N, Andersen HW, Morari M. Homogeneous azeotropic distillation: comparing entrainers. Can J Chem Eng. 1991;69: 1302-1319.

24. Shen WF, Benyounes H, Gerbaud V. Extension of thermodynamic insights on batch extractive distillation to continuous operation. 1. Azeotropic mixtures with a heavy entrainer. Ind Eng Chem Res. 2013;52:4606-4622.

25. Shen WF, Gerbaud V. Extension of thermodynamic insights on batch extractive distillation to continuous operation. 2. Azeotropic mixtures with a light entrainer. Ind Eng Chem Res. 2013;52:46234637.

26. Gerbaud V, Rodriguez-Donis I. Azeotropic distillation, In: Górak A, Olujic Z, editors. Distillation Book, vol. II, Chapter 6, Amsterdam: Elsevier, 2014:201-245.

27. Lang P, Modla G, Benadda B, Lelkes Z. Homoazeotropic distillation of maximum azeotropes in a batch rectifying column with continuous entrainer feeding. I. Feasibility studies. Comput Chem Eng. 2000;24:1665-1671.

28. Lang P, Modla G, Kotai B, Lelkes Z, Moszkowicz P. Homoazeotropic distillation of maximum azeotropes in a batch rectifying column with continuous entrainer feeding. II. Rigorous simulation results. Comput Chem Eng. 2000;24:1429-1435.

29. Van Dongen DB, Doherty MF. On the dynamics of distillation processes VI. Batch distillation. Chem Eng Sci. 1985;40:2087-2093.

30. Bernot C, Doherty MF, Malone MF. Feasibility and separation sequencing in multicomponent batch distillation. Chem Eng Sci. 1991;46:1311-1326.

31. Dussel R, Stichlmair J. Separation of azeotropic mixtures by batch distillation using an entrainer. Comput Chem Eng. 1995;19:S113S118.

32. Luyben W. Control of the Maximum-boiling acetone/chloroform azeotropic distillation system. Ind Chem Eng Res. 2008;47(16): 6140-6149.

33. Seader JD, Henley, Ernest J, Seader JD. Separation Process Principles, New York: Wiley, 1998. 
34. Gerbaud V, Rodriguez-Donis I, Extractive Distillation. Distillation: Equipment and Processes, Chapter 6, Oxford: Elsevier, 2014;02: 201-246

35. Hilmen E, Kiva V, Skogestad S. Topology of ternary VLE diagrams: elementary cells. AIChE J. 2003;48:752-759.

36. Shen WF, Benyounes H, Gerbaud V. A Review of extractive distillation advanced operation polices and strategies. Rev Chem Eng. 2015;31(1):13-26.

37. Laroche L, Bekiaris N, Andersen HW, Morari M. The curious behavior of homogeneous azeotropic distillation - implications for entrainer selection. AIChE J. 1992;38:1309-1328.

38. Ostergaad JJ. Fuzzy Logic Control of a Heat Exchange Process. Fuzzy Automata and Decision Processes, Amsterdam: North-Holland, 1977.

39. Tiverios PG, Van Brunt V, Extractive distillation solvent characterization and shortcut design procedure for methylcyclohexane-toluene mixtures. Ind Eng Chem Res. 2000;39(6):1614-1623.

40. Song J, Song H-H, Computer-aided molecular design of environmentally friendly entrainers for separation processes. Chem Eng Technol. 2008;31:177-187.

41. Momoh SO. Assessing the accuracy of selectivity as a basis for solvent screening in extractive distillation processes. Sep Sci Technol. 1991;26(5):729-742.

42. Pretel EJ, López A, Bottini SB, Esteban A. Computer-aided molecular design of entrainers for separation processes. AIChE J. 1994; 40(8):1349-1360.

43. Odele O, Macchietto S. Computer aided molecular design: a novel method for optimal solvent selection. Fluid Phase Equilib. 1993;82: 47-54.

44. Newhouse T, Baran PS, Hoffmann RW. The economies of synthesis. Chem Soc Rev. 2009;38(11):3010-3021.

45. Lang P, Yatim H, Moszkowicz P, Otterbein M. Batch Extractive Distillation under Constant Reflux Ratio. Comput Chem Eng. 1994; 18:1057-1069.

46. Gmehling J, Möllmann C. Synthesis of distillation processes using thermodynamic models and the Dortmund data bank. Ind Eng Chem Res. 1998;37:3112-3123.

47. Jork C, Kristen C, Pieraccini D, Stark A, Chiappe C, Beste Y-A, Arlt W. Tailor-made ionic liquids. J Chem Therm. 2005;37:537-558.

48. Simões MG, Friedhofer M. An implementation methodology of a fuzzy based decision support algorithm. Int J Knowledge Based Intell Eng Syst. 1997;1(4):267-275.

49. O' Neill A, Khan U, Nirmalraj PN, Boland J, Coleman JN. Graphene dispersion and exfoliation in low boiling point solvents. J Phys Chem. 2011;115(13):5422-5428.
50. Rodríguez A, Serrano L, Moral A, Pérez A, Jiménez L. Use of highboiling point organic solvents for pulping oil palm empty fruit bunches. Bioresour Technol. 2008;99(6):1743-1749.

51. Smallwood IM. Front matter. Handbook of Organic Solvent Properties. Butterworth-Heinemann: Oxford, 1996.

52. Katritzky AR, Mu L, Lobanov V. Correlation of boiling points with molecular structure. 1. A training set of 298 diverse organics and a test set of 9 simple inorganics. J Phys Chem. 1996;100(24):1040010407.

53. Schwarz CE, Nieuwoudt I. Phase equilibrium of propane and alkanes: Part I. Experimental procedures, dotriacontane equilibrium and EOS modelling. J Supercrit Fluids. 2003;27(2):133-144.

54. Takanohashi T, Iino M, Nakamura K. Evaluation of association of solvent-soluble molecules of bituminous coal by computer simulation. Energy Fuels. 1994;8(2):395-398.

55. Van Dyk B, Nieuwoudt I. Design of entrainers for extractive distillation. Ind Eng Chem Res. 2000;39(5):1423-1429.

56. Hostrup M, Harper PM, Gani R. Design of environmentally benign processes: integration of solvent design and separation process synthesis. Comput Chem Eng. 1999;23(10):1395-1414.

57. De Figueirêdo MF, Guedes BP, De Araújo JMM, Vasconcelos LGS, Brito RP. Optimal design of extractive distillation column- A systematic procedure using a process simulator. Chem Eng Res Des. 2011;89(3):341-346.

58. Langston P, Hilal N, Shingfield S. Simulation and optimization of extractive distillation with water as entrainer. Chem Eng Process: Process Intensif. 2005;44(3):345-351.

59. Kossack S, Kraemer K, Gani R, Marquardt W. A systematic synthesis framework for extractive distillation processes. In: Proceedings of European Congress of Chemical Engineering, Copenhagen. 2007; 16-20.

60. Arifin S, Chien IL. Design and control of an isopropyl alcohol dehydration process via extractive distillation using dimethyl sulfoxide as an entrainer. Ind Eng Chem Res. 2008;47:790-803.

61. Douglas JM. Conceptual Design of Chemical Processes, New York: McGraw-Hill, 1988.

62. Luyben WL. Distillation design and control using aspen ${ }^{T M}$ simulation. Wiley Online Library, 2006.

63. Marshall, Swift. Average M \& S index for year 2011. Chemical Engineering's PLANT COST INDEX database. 2012;119:84. 